\title{
Expression of AITR and AITR ligand in breast cancer patients
}

\author{
YON SEON KIM ${ }^{1}$, HYO WON JUNG ${ }^{2}$, JI CHOI ${ }^{2}$, BYUNG SAE KWON ${ }^{2}$, \\ SOO-YOUN HAM ${ }^{3}$, AE KYUNG JUNG ${ }^{4}$ and BYUNG KYUN KO ${ }^{1}$
}

\author{
${ }^{1}$ Department of Surgery, Ulsan University Hospital, Ulsan University College of Medicine, Ulsan 682-714; \\ ${ }^{2}$ The Immunomodulation Research Center, Department of Biological Sciences, University of Ulsan, Ulsan 680-749; \\ ${ }^{3}$ Department of Radiology, Korea University Hospital, Korea University College of Medicine, Seoul 136-705; \\ ${ }^{4}$ Department of Radiology, Ulsan University Hospital, Ulsan University College of Medicine, Ulsan 682-714, Korea
}

Received July 9, 2007; Accepted August 27, 2007

\begin{abstract}
Human activation-inducible TNF receptor (AITR) is a new member of the tumor necrosis factor family and expressed on peripheral blood mononuclear cells (PBMC) and leukocytes. Its ligand (AITRL) is expressed in endothelial cells. This study aimed to evaluate the presence and role of AITR and AITRL in patients with breast cancer. Expression of AITR and AITRL on PBMC and breast cancer cells was determined by flow cytometry, RT-PCR and fluorescence microscopy. Soluble (s) AITR and sAITRL were detected in serum of breast cancer patients by ELISA. AITR and AITRL were constitutively expressed in T cells, B cells, monocytes and monocyte-derived dendritic cells of breast cancer patients. AITRL was overexpressed in breast cancer cells. The levels of sAITRL were significantly increased in serum of breast cancer patients compared with the healthy control. This study suggests that AITR and AITRL may play an important role in tumor growth and survival in breast cancer.
\end{abstract}

\section{Introduction}

The members of the tumor necrosis factor (TNF) family are involved in the regulation of cell proliferation, differentiation and death and play a central role in the development of the immune response and in tumor killing (1). Human activationinducible tumor necrosis factor receptor (AITR) is a new member of the TNF family such as CD27, CD40, 4-1BB and OX-40 and exhibits a high homology to murine glucocorticoidinduced TNF receptor family-related gene (GITR; TNFRSF18)

Correspondence to: Dr Byung Kyun Ko, Department of Surgery, Ulsan University Hospital, Ulsan University College of Medicine, Ulsan 682-714, Korea

E-mail: kobyky@mail.ulsan.ac.kr

Key words: breast cancer, activation-inducible tumor necrosis factor receptor, activation-inducible tumor necrosis factor receptor ligand, cancer cell, soluble activation-inducible tumor necrosis factor receptor, tumor immunity
(2). There is a mismatch in the first cysteine-rich pseudorepeat between GITR and AITR, because the first pseudorepeat of GITR corresponds to the first TNFR cysteine-rich motif (3). AITR is expressed in human peripheral blood mononuclear cells and leukocytes and is induced with T cell activation (2). AITR associates with TNF-receptor-associated factors (TRAF) such as TRAF1, TRAF2 and TRAF3 and the interaction of AITR with its ligand (AITRL) activates nuclear factor

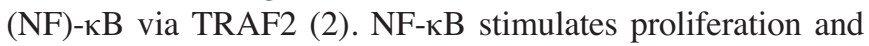
blocks apoptosis in different cell types, including human breast cancers $(4,5)$. Thus, breast cancer cells rely on $\mathrm{NF}-\kappa \mathrm{B}$ for aberrant cell proliferation and simultaneously avoid apoptosis (5). Overexpression of AITR mRNA was shown to rescue T cells from $\mathrm{T}$ cell receptor (TCR)-mediated cell death $(2,3)$. AITR ligand (AITRL) cloned from a human brain cDNA library and found to be expressed in human endothelial cells provided costimulatory signal in $\mathrm{T}$ cells activation $(2,3)$. However, AITR and AITRL are important for interaction between activated $\mathrm{T}$ lymphocytes and endothelial cells. Information on the biological functions of AITR and AITRL is limited. Based on GITR data, GITR may play a role in the negative regulation of $\mathrm{T}$ cell receptor (TCR)-derived $\mathrm{T}$ cell activation and apoptosis $(6,7)$. GITR as a receptor on the surface of $\mathrm{CD} 4{ }^{+} \mathrm{CD} 25^{+}$regulatory $\mathrm{T}$ cells (Treg) and can modulate Treg function in actively maintaining peripheral tolerance, GITR signaling had a costimulatory effect on purified conventional $\mathrm{CD}^{+} \mathrm{CD} 25^{-} \mathrm{T}$ cells $(8,9)$. GITR is coexpressed with $\mathrm{CD} 25$ on the $\mathrm{CD} 4^{+} \mathrm{T}$ cells in human peripheral blood and patients with non-infectious uveitis and participate in the inflammatory process (10). The presence of tumorspecific Treg cells expressing CD25 and GITR at tumor sites may have a profound effect on the inhibition of $\mathrm{T}$ cell responses against cancer (11). Engagement of GITR on effector $\mathrm{T}$ cells by its ligand mediates resistance to suppression by $\mathrm{CD} 4{ }^{+} \mathrm{CD} 25^{+} \mathrm{T}$ cells (12). GITRL is constitutively expressed on cultured retinal pigment epithelium and in high levels on photoreceptor inner segments (13). But little is known about the expression profiles of GITR in human peripheral T cells either in healthy individuals or in the patients with autoimmune diseases and cancer.

In the present study, we analyzed the expression of AITR and AITRL in PBMC and cancer cells of breast cancer patients compared with healthy individuals. 


\section{Materials and methods}

Patients. A total of 20 females with breast cancer of stages I or II with a median age of 42 (range, 31-61) years were included in the investigation. In all patients, tumor stage, histologic grading, axillary lymph node involvement and hormone receptor status were determined by routine histopathological examination. As controls, 20 healthy, age-matched females without clinical, radiological and serological evidence of the presence of breast cancer with a median age of 35 (range, 22-53) were included. Clinical characteristics of all patients are presented in Table I.

Clinical samples. The samples of breast cancer patients were from those who underwent an endoscopic biopsy, diagnostic or curative operations. Peripheral blood samples from breast cancer patients and healthy individuals were collected during the same period of this study. Tumor and normal tissues of breast cancer patients for flow cytometry and immunohistochemistry were from fresh specimens of resection surgery. All samples were obtained with the patients consent and were approved by our local Ethics Committee.

Cell isolation and culture. Peripheral blood mononuclear cells (PBMC) were isolated from breast cancer patients and healthy individuals by Ficoll-Hypaque (Pharmacia, Uppsala, Sweden) gradient centrifugation from freshly drawn heparinized peripheral venous blood, washed 3 times in 1x PBS and resuspended to $1 \times 10^{6} \mathrm{PBMC} / \mathrm{ml}$ in RPMI-1640 medium supplemented with $10 \%$ fetal bovine serum (FBS) and antibiotics at $37^{\circ} \mathrm{C}$ in $5 \% \mathrm{CO}_{2}$ incubator. To obtain monocytes, non-adherent cells of PBMC were removed following $2 \mathrm{~h}$ incubation at $37^{\circ} \mathrm{C}$ in $\mathrm{CO}_{2}$ incubator and adherent cells were

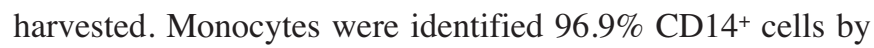
flow cytometry. To acquire maturate dendritic cells, monocytes were cultured with $100 \mathrm{U} / \mathrm{ml}$ of GM-CSF and $1,000 \mathrm{U} / \mathrm{ml}$ of IL-4 for 6 days. Immature monocyte-derived dendritic cells were cultured with $500 \mathrm{U} / \mathrm{ml} \mathrm{TNF}-\alpha$. The matured dendritic cells were made up of $98 \%$ CD $11 \mathrm{c}^{+}$cells. The biopsy cancer tissues were mined into 1- to 3-mm fragments. Single tumor cells were released by enzymatic digestions with $0.25 \%$ trypsin (Invitrogen Life Technologies, Carlsbad, CA), collagenase I $(400 \mathrm{U} / \mathrm{ml})$, collagenase II $(1,000 \mathrm{U} / \mathrm{ml})$ and hyaluronidase $(1 \mathrm{mg} / \mathrm{ml})$ (Sigma, St. Louis, MO). Tumor cells/ml $\left(1 \times 10^{6}\right)$ were plated in RPMI-1640 medium with $10 \%$ FBS and antibiotics. After 2-3 days, the primary cells were typsinized and assessed the expression of AITR and AITRL by flow cytometry and fluorescence microscopy.

Antibodies. Monoclonal antibodies (mAbs) against AITR (anti-AITR mAbs; clone 621 and 913) and AITRL (anti-
AITRL mAbs; clone CE2 and BB4) were purchased from ImmunoMics (Ulsan, Korea). Anti-AITR and anti-AITRL mAbs were directly conjugated with fluorescein-isothiocyanate (FITC). PE-conjugated monoclonal antibodies (MAbs) directed against CD4, CD8, CD19, CD14 and CD11c (R\&D Systems, Minneapolis, MN) were used for cell subset typing. FITC-conjugated mouse IgG1 antibodies (BD PharMingen, San Diego, CA) were used as controls.

Flow cytometry. PBMC were stimulated with $1 \mu \mathrm{g} / \mathrm{ml}$ of antiCD3 (OKT3) and PHA (5 $\mu \mathrm{g} / \mathrm{ml})$ for $24 \mathrm{~h}$ or not. Cells were washed 1x PBS containing $1 \%$ BSA and $0.1 \%$ sodium azide (FACs buffer) once and subjected to flow cytometry in FACS Calibur to determine expression profiles of AITR and AITRL on lymphocyte subsets. PBMC were stained with FITCconjugated anti-AITR or anti-AITRL mAbs and its expression was analyzed by single-color flow cytometry on FACSCalibur and CELLQuest (Beckton Dickinson, Mountain View, CA). To determine the expression profiles of AITR and AITRL on cell subsets, PBMC were stained with FITCconjugated anti-AITR or anti-AITRL mAbs on PE-conjugated antibodies to T cell marker; and CD8 and B cell marker; CD19 for $30 \mathrm{~min}$ at $4^{\circ} \mathrm{C}$. The samples were washed twice with FACs buffer. Monocytes, monocyte-derived dendritic cells and breast cancer cells were also incubated with FITC-conjugated anti-AITR and anti-AITRL mAbs for $30 \mathrm{~min}$ at $4^{\circ} \mathrm{C}$ and then washed twice with FACs buffer. The proportion of $\mathrm{AITR}^{+}$and $\mathrm{AITRL}^{+}$cells were analyzed by single-color flow cytometry. Matching isotype antibodies were used as a control. All mAbs were the same and the flow cytometry was calibrated before each assay using FACSComp software (Beckton Dickinson).

Serum sAITRL. Serum levels of soluble AITR (sAITR) and soluble AITRL (sAITRL) were measured by an enzyme-linked immunosorbent assay (ELISA). Serum samples were isolated from peripheral blood of all subjects by centrifugation and frozen immediately following collection. All assays were thawed before assay. Nunc Maxisorb ELISA plates were coated overnight with $1 \mu \mathrm{g} / \mathrm{ml}$ anti-AITR (clone 621; ImmunoMics) or anti-AITRL (clone CE2, ImmunoMics) in $0.05 \mathrm{M} \mathrm{NaHCO}_{3}$ buffer at $4^{\circ} \mathrm{C}$. After washing with $1 \mathrm{x}$ PBS containing $0.1 \%$ Tween-20, the plates were blocked with $4 \%$ BSA in $1 \mathrm{x}$ PBS for $1 \mathrm{~h}$ at $37^{\circ} \mathrm{C}$. The serum samples were diluted with PBS containing $0.1 \%$ Tween-20 and $1 \%$ BSA and incubated for $2 \mathrm{~h}$ at $37^{\circ} \mathrm{C}$. The plates were washed incubated with incubated biotinylated anti-AITR (clone 913) or antiAITRL (clone BB4) for $1 \mathrm{~h}$ at $37^{\circ} \mathrm{C}$. They were then washed and developed with TMB peroxidase substrate system (Endogen, BD Biosciences, MN, USA). The reaction was stopped after $20 \mathrm{~min}$ at room temperature (RT) with $0.1 \mathrm{~N}$

Table I. Characteristics of patients with breast cancer and of healthy control women.

Characteristics

Healthy controls

Patients with breast cancer stages I or II

No. of patients

Median age (range)

35 (22-53)

42 (31-61)

Metastasis 
a)

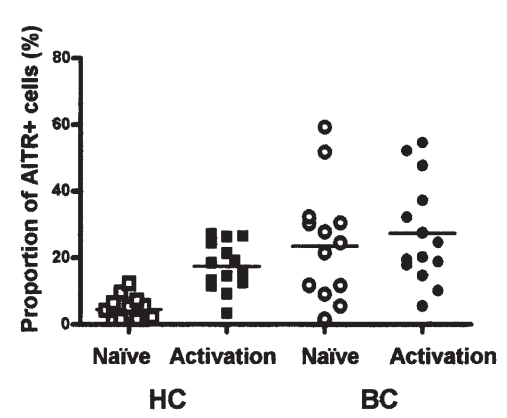

b)

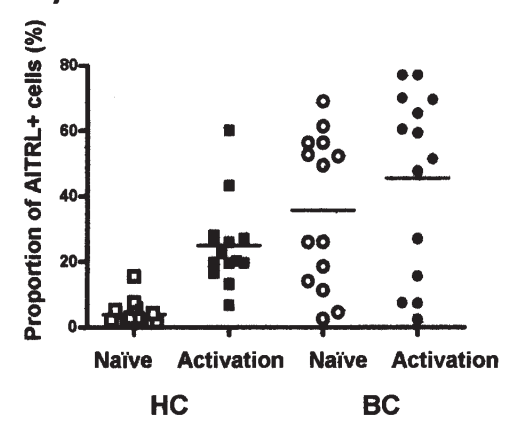

Figure 1. Expression levels of AITR (a) and AITRL (b) in breast cancer. PBMC were cultured in the absence (naïve) or presence (activation) of anti-CD3 $\mathrm{mAb}(1 \mu \mathrm{g} / \mathrm{ml})$ and PHA $(5 \mu \mathrm{g} / \mathrm{ml})$. PBMC were stained with FITC-conjugated anti-AITR and anti-AITRL mAbs and analyzed for its expression by flow cytometry after $24 \mathrm{~h}$. Horizontal bars depict means $(n=20)$. HC, healthy control; BC, breast cancer.

$\mathrm{H}_{2} \mathrm{SO}_{4}$ and $\mathrm{OD}_{450} \mathrm{~nm}$ was subsequently measured. Purified human recombinant AITR-GST or AITRL-GST (Immunomics) were used as standards. ELISA sensitivity was $50 \mathrm{pg} / \mathrm{ml}$.

RT-PCR. mRNA expression of AITR and AITRL were determined by reverse transcriptase RT-PCR as previously described by Kwon et al (2). Total RNA was extracted from freshly isolated PBMC and tumor tissues using the RNeasy kit (Qiagen, Countaboeuf, France) following the manufacturer's recommendations. The single-strand cDNA was synthesized using $1 \mu \mathrm{g}$ of total RNA by reverse-transcription using an oligo-dT primer (GenoTec, Korea). Primer sequences were as follows: (a) AITR: 5'-GAG GAG TGC TGT TCC GAG T-3'; 5'-ACA CCC ACA GGT CTC CCA G-3'; and (b) AITRL: 5'-AAG CTG TGG CTC TTT TGC TC-3'; 5'-GAA TTG GGG ATT TGC CAG TA-3'. The samples were denatured at $95^{\circ} \mathrm{C}$ for $30 \mathrm{sec}$, followed by 40 cycles of amplification $\left(95^{\circ} \mathrm{C}\right.$ for $0 \mathrm{sec} ; 55^{\circ} \mathrm{C}$ for AITR and $50^{\circ} \mathrm{C}$ for AITRL, $60 \mathrm{sec}$; and $72^{\circ} \mathrm{C}, 60 \mathrm{sec}$ ). The PCR products of AITR and AITRL were each 514 and $540 \mathrm{bp}$ fragments. The amplified fragments were size-separated on a $1 \%$ agarose gel and visualized by ethidium bromide.

Confocal laser scanning microscopy. Tumor tissues were separately snap-frozen in Tissue-Tek OCT (Miles Diasnostics, Elkhart, IN, USA) and stored at $-80^{\circ} \mathrm{C}$ until used. Cryostat sections $6 \mu \mathrm{m}$ thick were mounted on glass slides (Superior, Marienfeld, Germany). The glass slides were boxed and stored at $-20^{\circ} \mathrm{C}$ until immunological analysis. The slides were rinsed 3 times with $1 \mathrm{x}$ PBS for $10 \mathrm{~min}$ and blocked with $10 \%$ normal goat serum in $1 \mathrm{x}$ PBS for $1 \mathrm{~h}$ at room temperature. The slides were stained with FITC-conjugated anti-AITR (clone 621) and anti-AITRL (clone CE2) in the dark at room temperature for $1 \mathrm{~h}$. After washing, slides were sealed with aqueous mounting media and analyzed by confocal laser scanning microscopy (LSM 510, Carl Zeiss, Heidelberg, Germany) equipped with Ar and HeNe lasers. Control mAb were used FITC-conjugated anti-mIgG at the same concentrations in each assay.

Statistical analysis. Statistical analysis was performed with software of SNPP for analyzing of AITRL data, which were shown as mean $\pm \mathrm{SD}$. The independent-samples t-test, Chi- square test and Person correlation analysis were assessed to compare variables of serum levels of sAITRL between BC patients and healthy individuals. A p-value of $<5 \%$ was considered statistically significant.

\section{Results}

Expression of AITR and AITRL. At first we gated lymphocyte population from PBMC on forward- and side-scatter plot and then detected FITC-conjugated $\mathrm{AITR}^{+}$or $\mathrm{AITRL}^{+}$cells (Fig. 1). Expression level of AITR (Fig. 1a) showed higher levels $(\mathrm{P}<0.05)$ on PBMC of breast cancer patients (mean \pm $\mathrm{SD} ; 25.0 \pm 12.4 \%)$ than that of healthy individuals $(15.1 \pm 9.58 \%)$ after stimulation. AITR was expressed on activated $\mathrm{CD}^{+} / \mathrm{CD}^{+} \mathrm{T}$ cells and $\mathrm{CD} 19^{+} \mathrm{B}$ cells in the lymphocyte population of healthy individuals $(4.02 \pm 2.87 \%)$, but on the other hand it was constitutively expressed on resting cells of breast cancer patients $(22.66 \pm 16.12 \%)$. AITRL (Fig. 1b) expressed low levels on resting PBMC of healthy individuals or did not $(2.16 \% \pm 0.86 \%)$, and its levels were increased after stimulation $(22.07 \pm 9.89 \%)$. AITRL was constitutively expressed on resting PBMC (36.28 $\pm 19.99 \%)$ of $\mathrm{BC}$ patients and slightly increased on activated PBMC $(48.56 \pm 25.62 \%)$. AITRL expression was observed on $\mathrm{CD}^{+} / \mathrm{CD}^{+} \mathrm{T}$ cells, CD19+ $\mathrm{B}$ cells, monocytes and dendritic cells in breast cancer patients and its patterns were similar to AITR. AITR and AITRL were also highly expressed on monocytes and monocyte-derived dendritic cells of breast cancer patients (Fig. 2). Both AITR (20.14 \pm 6.96$)$ and AITRL $(64.06 \pm 14.57)$ were highly expressed in cancer cells isolated from breast tissues of breast cancer patients (Fig. 3) compared with normal cells isolated from normal tissues (AITR, $20.14 \pm 6.96 \%$ and AITRL, 23.09 $\pm 10.51 \%$ ).

Serum sAITR and sAITRL. Serum sAITR and sAITRL levels were determined by ELISA with 20 breast cancer patients compared with healthy individuals (Fig. 4). Serum s4-1BB in both the breast cancer patient group (mean \pm SD; $170.8 \pm 108.9$ $\mathrm{pg} / \mathrm{ml})$ and the healthy control group $(54.9 \pm 60.7 \mathrm{pg} / \mathrm{ml})$ detected low concentrations of sAITR. The serum levels of SAITRL were remarkably elevated in breast cancer patients $(1,429.3 \pm 1,043.5 \mathrm{pg} / \mathrm{ml})$ compared with the healthy control group $(170.8 \pm 108.9 \mathrm{pg} / \mathrm{ml})$. The data suggest that the serum 
c)

Mo
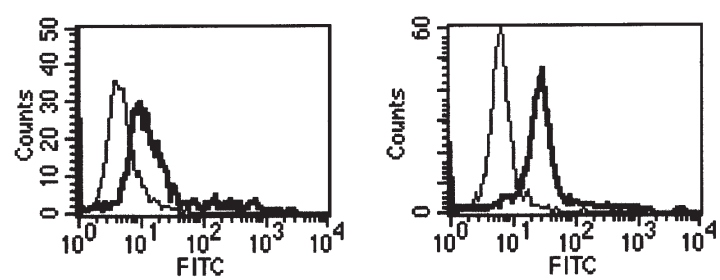

DCs
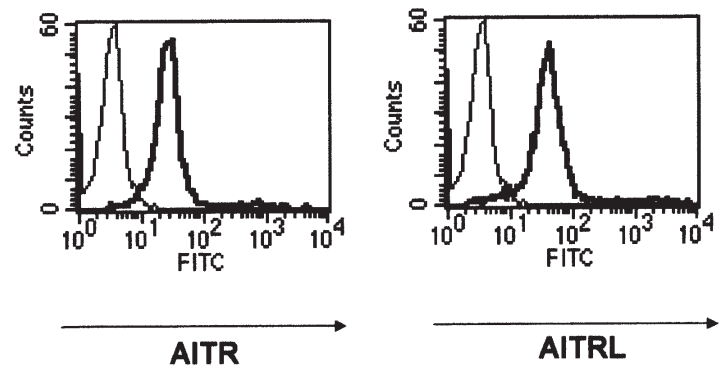

Figure 2. Expression levels of AITR and AITRL in monocytes and dendritic cells of the patients with breast cancer. To acquire dendritic cells (DCs), monocytes (Mo) were cultured with GM-CSF (100 U/ml), IL-4 (1,000 U/ml) and TNF- $\alpha(500 \mathrm{U} / \mathrm{ml})$ for 6 days. Cells were stained with FITC-conjugated anti-AITR and anti-AITRL mAbs and analyzed the expression of AITR and AITRL by single-color flow cytometry.

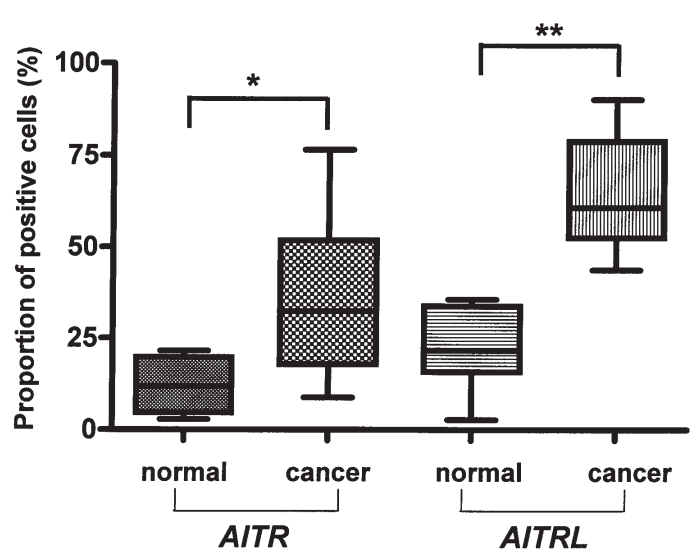

Figure 3. Expression levels of AITR and AITRL in cancer cells of patients with breast cancer. Normal or cancer cells were freshly isolated from the biopsy cancer tissues of the patients with breast cancer and stained with FITC-conjugated anti-AITR and anti-AITRL. Expression levels of AITR and AITRL were determined by flow cytometry. The primary cells used in this figure were cultured within five passages of the initial culture. Bars depict means $(n=20) .{ }^{\dagger} P<0.001$; and ${ }^{\ddagger} P<0.0001$ compared with the expression levels in healthy individuals.

level of SAITRL is greatly increased in breast cancer patients and correlates with high expression of AITRL on PBMC of breast cancer patients.

$R T-P C R$. To identify the mRNA expression of AITR and AITRL on breast cancer cells of BC patients, we carried out RT-PCR (Fig. 5). RT-PCR analysis revealed an almost complete absence of AITRL mRNA in cancer cells isolated from breast tissues of BC patients. The integrity of the RNA preparation was confirmed by the detection of mRNA for the housekeeping $\beta$-actin (data not shown).

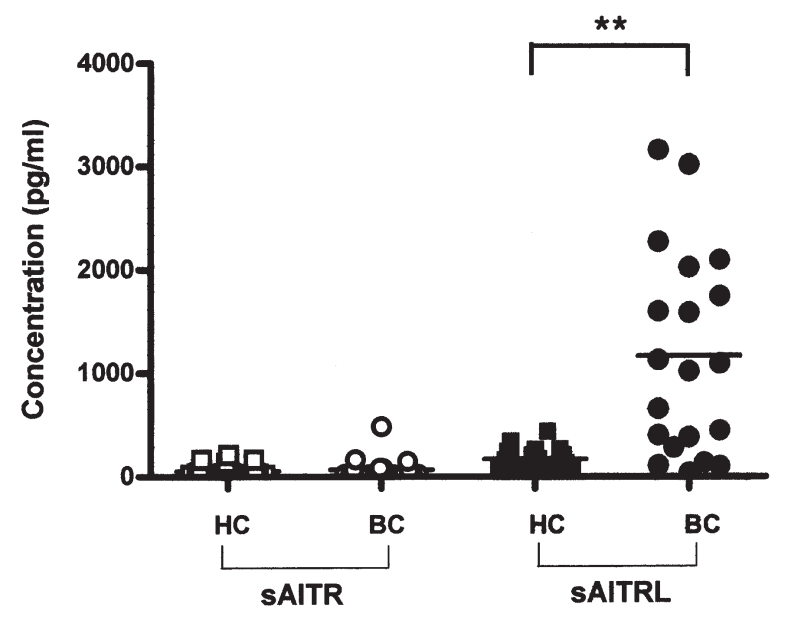

Figure 4. sAITR and sAITRL in sera of the patients with breast cancer. SAITR and sAITRL were investigated in serum samples of the patients with breast cancer by ELISA. ${ }^{\ddagger} \mathrm{P}<0.0001$ compared with serum levels in the healthy control. Bars are shown as means $(n=20)$. HC, healthy control; $B C$, breast cancer.

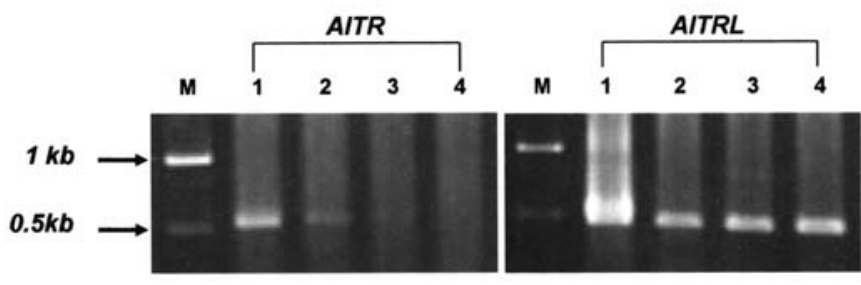

Figure 5. mRNA expression of AITR and AITRL in cancer cells of the patients with breast cancer. The expression of AITR/AITRL transcripts was evaluated by RT-PCR. Each gene was amplified using specific primer sets, and the PCR products were analyzed by $1.5 \%$ agarose gel electrophoresis. $\mathrm{M}$, size marker; and lanes 1-4, four different patients with breast cancer.

Immunohistochemical analysis. To confirm that breast cancer cells can express AITR and AITRL, we analyzed breast tissues of breast cancer patients by immunohistochemistry analysis using anti-AITR and anti-AITRL mAbs compared with nontumor normal tissues. The cancer tissues of breast cancer patients exhibited typical pathologic figures of breast cancer, including increased vascularity as shown by H\&E staining (Fig. 6a). AITRL expression was observed in cancer tissues of breast cancer patients with rich regions of the tumors (Fig. 6b). AITRL expression was observed in tumor cells isolated from cancer tissues of breast cancer patients (Fig. 6c). In contrast, AITR expression was not detected in breast cancer cells of the breast tissue (data not shown).

\section{Discussion}

Expression of costimulatory molecules conferred the ability to deliver a costimulatory signal and improved the antigen presentation capability of the tumor cells to patient $\mathrm{T}$ cells in vitro (14). It has been demonstrated that breast cancer cells can escape immune surveillance through abnormal expression of MHC II antigen and CD80/CD86 $(15,16)$. A defective expression of CD54 and its regulation via TNF- $\alpha, \mathrm{CD} 80$ and 


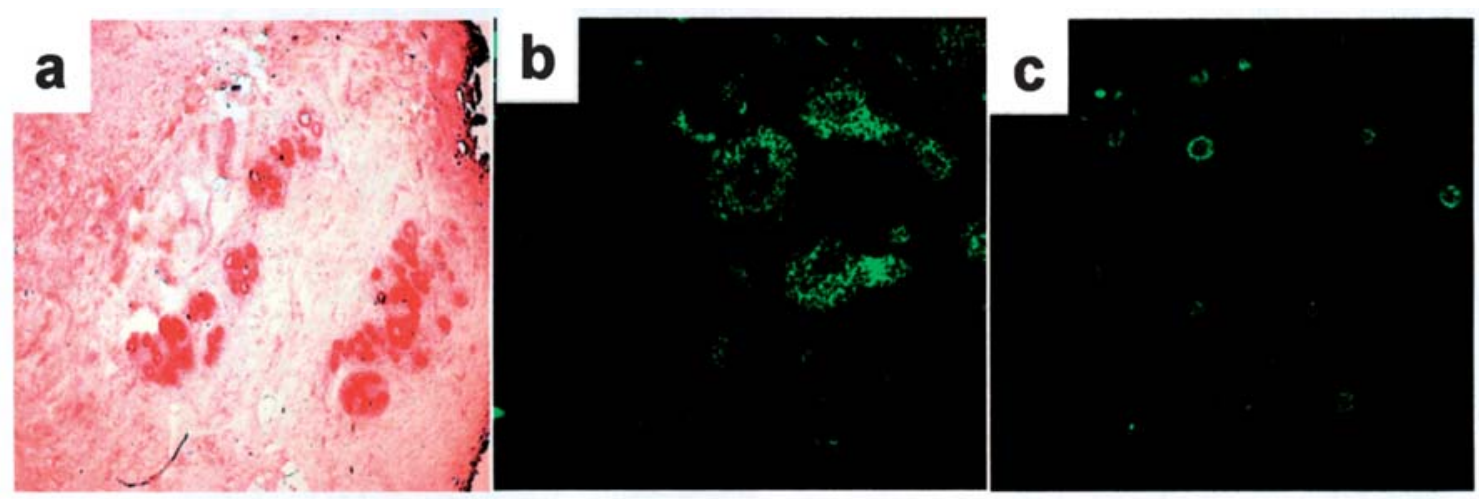

Figure 6. AITRL expression in breast cancer cells of the patients with breast cancer. Breast cancer tissues of the patient with breast cancer were stained with H\&E (a), with FITC-conjugated anti-AITRL mAb (b). Breast cancer cells were isolated from the cancer tissue and stained with FITC-conjugated with antiAITRL mAb (c). The green color indicates AITRL-positive immunoreactivity.

CD86 may contribute to tolerance of the immune system towards the presence of malignant cells in early breast cancer patients (17). ICAM-1 expression plays an important role in the interaction of tumor cells and effector $\mathrm{T}$ cells of the immune system in breast cancer (18). Programmed death-1 ligand (PD-L1) is highly expressed on malignant cells of the breast and attenuates the antitumor immune responses through $\mathrm{CD}^{+} \mathrm{T}$ cell-mediated cytolysis (19). We confirmed the expression of AITR and AITRL in PBMC with breast cancer patients compared with healthy individuals by flow cytometric analysis (Fig. 1). AITR and AITRL were expressed in activated PBMC with healthy individuals, while they were constitutively expressed in PBMC with breast cancer patients. The expression of AITR and AITRL was observed in $\mathrm{CD}^{+} / \mathrm{CD}^{+} \mathrm{T}$ cells and $\mathrm{CD} 19^{+} \mathrm{B}$ cells (data not shown). AITR and AITRL were highly expressed on monocytes and monocyte-derived dendritic cells of two groups with similar patterns (Fig. 2). We found that breast cancer cells can highly express AITRL (Fig. 3). We confirmed that AITRL was strongly expressed in breast cancer tissues by RTPCR (Fig. 5) and confocal laser scanning microscopy (Fig. 6). AITR is expressed in PBMC of healthy individuals after TCR activation with PMA/ionomysin or anti-CD3 plus antiCD28 mAbs (2). In contrast, AITRL is constitutively expressed in human umbilical vein endothelial cells (HUVEC) and primary endothelial cells in blood vessels and its expression was up-regulated after stimulation with LPS. Therefore, Kwon et al (2) concluded that AITR and AITRL is important for interactions between activated $\mathrm{T}$ lymphocytes and blood vessels. GITR is a CD4 ${ }^{+} \mathrm{T}$ cell activation marker similar to other $\mathrm{T}$ cell markers such as CD69, CD25 and HLA-DR human peripheral blood and its expression correlates with the clinical course of non-infectious uveitis (20). In GITR deficient mice, it was suggested that GITR might be important for the negative regulation of $\mathrm{T}$ cell activation (7). GITR, which is preferentially expressed on the surface of Treg, potentially provides a signal that abrogates Treg suppression (9). GITRL is constitutively expressed on retinal pigment epithelium and photoreceptor inner segments in high levels and participates in the regulation of ocular inflammation (13). GITRL may be the crucial factor for tumorigenesis and the aggressive biological behavior of human peripheral primitive neuroectodermal tumor (21). Our findings suggest that increasing expression of GITR and GITRL plays a role in $\mathrm{T}$ cell apoptosis and may have implications in understanding immunogenicity of breast cancer.

Several members of the TNF superfamily, such as CD27, CD30, CD137, FasL and TNF- $\alpha$, TRAIL have greatly generated stable soluble forms and selectively induced apoptosis in many transformed cells (22). A soluble Fas generated by several alternative mRNA splicing can bind FasL and block Fas-mediated apoptosis (23). Apoptosis is an important control mechanism in the regulation of tumor progression and metastasis because tumor growth depends on uncontrolled proliferation and the suppression of apoptosis (24). Gastro-intestinal tumors may escape FasL-dependent immune-cytotoxic attack by overexpressing DcR3 that blocks FasL (25). Serum sFas levels may be a valuable clinical prognostic factor in predicting an outcome of disease progression for patients with metastatic breast cancer (26). Soluble FasL was eluted from the surface of uveal melanomas specifically inhibited cytotoxic T lymphocyte lysis of tumor cells pretreated with an inhibitor of metalloproteases (27). sGITR triggered an inflammatory process in peritoneal membrane and neighboring fat tissues as an antagonist and blocks a tonic anti-inflammatory effect of GITRL (28). sGITRL in mice induces GITR-dependent NF$\kappa \mathrm{B}$ activation and blocks in vitro suppression mediated by both resting and activated Treg cells (29). We found that serum sAITRL level was significantly increased in breast cancer patients compared with the healthy control and corresponds with surface expression levels of AITRL (Fig. 4). This result suggests that SAITRL may play a role in tumor cell survival of breast cancer.

$\mathrm{NF}-\kappa \mathrm{B}$ stimulates proliferation and blocks apoptosis in different cell types, including human breast cancers $(4,5)$. Therefore, certain breast cancer cells rely on $\mathrm{NF}-\kappa \mathrm{B}$ for aberrant cell proliferation and simultaneously avoid apoptosis (5). NF- $\mathrm{BB}$ inhibits cell death and promotes faster cancer growth, migration and metastasis (30). AITRL is able to trigger AITR-specific $\mathrm{T}$ cell activation with strong induction of NF- $\mathrm{KB}$ and TRAF-2 (2). We have further completed characterization of the mechanisms that regulate the magnitude and duration of AITRL expression which 
should offer potential therapeutic targets for modulation of tumor immune response.

In conclusion, we reported for the first time on an analysis of the expression of AITR and AITRL in peripheral blood and cancer cells of patients with breast cancer. Our study supports the hypothesis that AITR and AITRL may contribute to tumor growth and survival.

\section{Acknowledgements}

This study was supported by the Science Research Center Fund to the IRC at the University of Ulsan, by KOSEF (KRF2001-015-DP0553) and by grants from the Korean Research Foundation (DP0553).

\section{References}

1. Aggarwal BB and Natarajan K: Tumor necrosis factors: developments during the last decade. Eur Cytokine Netw 7: 93-124, 1996.

2. Kwon B, Youn BS and Kwon BS: Functions of newly identified members of the tumor necrosis factor receptor/ligand superfamilies in lymphocutes. Curr Opin Immunol 11: 340-345, 1999.

3. Gurney P: General practice. Counsel homes. Health Serv J 109: 29, 1999.

4. Nakshatri H, Bhat-Nakshatri P, Martin DA, Goulet RJ Jr and Sledge GW Jr: Constitutive activation of NF-kappaB during progression of breast cancer to hormone-independent growth. Mol Cell Biol 17: 3629-3639, 1997.

5. Biswas DK, Shi Q, Baily S, Strickland I, Ghosh S, Pardee AB and Iglehart JD: NF-kappa B activation in human breast cancer specimens and its role in cell proliferation and apoptosis. Proc Natl Acad Sci USA 101: 10137-10142, 2004.

6. Nocentini G, Giunchi L, Ronchetti S, Krausz LT, Bartoli A and Moraca R: A new member of the tumor necrosis factor receptor family inhibits T cell receptor-induced apoptosis. Proc Natl Acad Sci USA 94: 6216-6221, 1997.

7. Ronchetti S, Nocentini G, Riccardi C and Pandolfi PP: Role of GITR in activation response of $\mathrm{T}$ lymphocytes. Blood 100: 350-352, 2002.

8. Sakaguchi S: Regulatory T cells: key controllers of immunologic self-tolerance. Cell 101: 455-458, 2000.

9. Ermann J and Fathman CG: Costimulatory signals controlling regulatory T cells. Proc Natl Acad Sci USA 100: 15292-15293, 2003.

10. Kwon B, Kim BS, Cho HR, Park JE and Kwon BS: Involvement of tumor necrosis factor receptor superfamily (TNFRSF) members in the pathogenesis of inflammatory diseases. Exp Mol Med 35: 8-16, 2003.

11. Wang HY, Lee DA, Peng G, Guo Z, Li Y, Kiniwa Y, Shevach EM and Wang RF: Tumor-specific human CD4+ regulatory $\mathrm{T}$ cells and their ligands: implications for immunotherapy. Immunity 20 : 107-118, 2004.

12. Stephens GL, Mchugh RS, Whitters MJ, Young DA, Luxenberg D, Carreno BM, Collins M and Shevach EM: Engagement of glucocorticoid-induced TNFR family-related receptor on effector $\mathrm{T}$ cells by its ligand mediates resistance to suppression by $\mathrm{CD}^{+} \mathrm{CD} 25^{+} \mathrm{T}$ cells. J Immunol 173: 5008-5020, 2004.

13. Kim BJ, Li Z, Fariss RN, Shen de F, Mahesh SP, Egwuagu C, Yu CR, Nagineni CN, Chan CC and Nussenblatt RB: Constitutive and cytokine-induced GITR ligand expression on human retinal pigment epithelium and photoreceptors. Invest Ophthalmol Vis Sci 45: 3170-3176, 2004.

14. Dols A, Smith JW 2nd, Meijer SL, Fox BA, Hu HM, Walker E, Rosenheim S, Moudgil T, Doran T, Wood W, Seligman M, Alvord WG, Schoof D and Urba WJ: Vaccination of women with metastatic breast cancer, using a costimulatory gene (CD80)modified, HLA-A2-matched, allogeneic, breast cancer cell line: clinical and immunological results. Hum Gene Ther 14: 1117-1123, 2003.
15. Fan P, Wang S, Liu X, Zhen L and Wu Z: Major histocompatibility complex class II antigen and costimulatory molecule expression on the surface of breast cancer cells. Zhonghua Zhong Liu Za Zhi 24: 327-330, 2002.

16. Dan HL, Zhao Y, Zhang J and Zhang JR: In vitro regulation of HLA and B7 expression in multidrug-resistant breast cancer cells. Di Yi Jun Yi Da Xue Xue Bao 22: 107-110, 2002.

17. Wolfram RM, Budinsky AC, Brodowicz T, Kubista M, Kostler WJ, Kichler-Lakomy C, Hellan M, Kahlhammer G, Wiltschke C and Zielinski CC: Defective antigen presentation resulting from impaired expression of costimulatory molecules in breast cancer. Int J Cancer 88: 239-244, 2000.

18. Komi J and Lassila O: Toremifene increase the expression of intercellur adhesion molecule-1 (ICAM-1) on MCF-7 breast cancer cells and Jurkat cells. Scand J Immunol 51: 73-78, 2000.

19. Brown JA, Dorfman DM, Ma FR, Sullivan EL, Munoz O, Wood CR, Greenfield EA and Freeman GJ: Blockade of programmed death-1 ligands on dendritic cells enhances $\mathrm{T}$ cell activation and cytokine production. J Immunol 170: 1257-1266, 2003.

20. Li Z, Mahesh SP, Kim BJ, Buggage RR and Nussenblatt RB: Expression of glucocorticoid induced TNF receptor family related protein (GITR) on peripheral T cells from normal human donors and patients with non-infectious uveitis. J Autoimmun 21: 83-92, 2003.

21. Chow SN, Lin MC, Shen J, Wang S, Jong YJ and Chien CH: Analysis of chromosome abnormalities by comparative genomic hybridization in malignant peripheral primitive neuroectodermal tumor of the ovary. Gynecol Oncol 92: 752-760, 2004.

22. Secchiero P, Vaccarezza M, Gonelli A and Zauli G: TNF-related apoptosis-inducing ligand (TRAIL): a potential candidate for combined treatment of hematological malignancies. Curr Pharm 10: 3673-3681, 2004.

23. Ruberti G, Cascino I, Papoff G and Eramo A: Fas splicing variants and their effect on apoptosis. Adv Exp Med Biol 406: 125-134, 1996.

24. Folkman J: Angiogenesis and apoptosis. Semin Cancer Biol 13: 159-167, 2003.

25. Pitti RM, Marsters SA, Lawrence DA, Roy M, Kischkel FC, Dowd P, Huang A, Donahue CJ, Sherwood SW, Baldwin DT, Godowski PJ, Wood WI, Gurney AL, Hillan KJ, Cohen RL, Goddard AD, Botstein D and Ashkenazi A: Genomic amplification of a decoy receptor for Fas ligand in lung and colon cancer. Nature 396: 699-703, 1998.

26. Bewick M, Conlon M, Parissenti AM, Lee H and Zhang L: Soluble Fas (CD95) is a prognostic factor in patients with metastatic breast cancer undergoing high-dose chemotherapy and autologous stem cell transplantation. J hematother Stem Cell Res 10: 759-768, 2001.

27. Hallermalm K, De Geer A, Kiessling R, Levitsky V and Levitskaya J: Autocrine secretion of Fas ligand shields tumor cells from Fas-mediated killing by cytotoxic lymphocytes. Cancer Res 64: 6775-6782, 2004.

28. Shin DH, Kwon BS, Chang YP, Bad SR, Kim J and Kim JW: Ultramicroscopical immunolocalization of PAX6 in the adult chicken retina. Acta Histochem 105: 267-272, 2003.

29. Ji HB, Liao G, Faubion WA, Abadia-Molina AC, Cozzo C, Laroux FS, Caton A and Terhorst C: Cutting edge: the natural ligand for glucocorticoid-induced TNF receptor-related protein abrogates regulatory $\mathrm{T}$ cell suppression. J Immunol 172: 5823-5827, 2004.

30. Huber MA, Azoitei N, Baumann B, Grunert S, Sommer A, Pehamberger $\mathrm{H}$, Kraut $\mathrm{N}$, Beug $\mathrm{H}$ and Wirth T: NF-kappaB is essential for epithelial-mesenchymal transition and metastasis in a model of breast cancer progression. J Clin Invest 114: 569-581, 2004. 